\title{
INFLUÊNCIA DO PH NA MORFOLOGIA E REMOÇÃO DE MAGNÉSIO DO LICOR DE LIXIVIAÇÃO DO NÍQUEL*
}

\section{Resumo}

Kristine Bruce Wanderley ${ }^{1}$

Denise Crocce Romano Espinosa² Jorge Alberto Soares Tenório ${ }^{3}$

A lixiviação com ácido sulfúrico de minérios lateríticos resulta na geração de enormes volumes de rejeito que são encaminhados para barragens de rejeitos. Todavia, é possível recuperar os metais perdidos e contidos nas barragens. Dentre os metais presentes no rejeito está o magnésio, que pode ser removido por cristalização a alta temperatura. Fatores como temperatura, $\mathrm{pH}$, agitação e tempo de residência podem afetar o produto final e remoção do magnésio da solução. Portanto, o presente estudo propõe avaliar a influência do $\mathrm{pH}$ na remoção de $\mathrm{Mg}^{2+}$ de uma solução sintética e analisar a morfologia dos cristais formados. A técnica empregada foi a cristalização a alta temperatura e pressão, realizada em um reator sob pressão. $\mathrm{O} \mathrm{pH}$ foi variado na faixa de 1-5 utilizando-se $\mathrm{H}_{2} \mathrm{SO}_{4} 1 \mathrm{M}$. A temperatura, tempo de residência e agitação foram mantidos constantes a $230^{\circ} \mathrm{C}, 5$ horas e $1000 \mathrm{rpm}$, respectivamente. A solução residual foi analisada por cromatografia de íons e a morfologia dos cristais por MEV-EDS. A maior remoção do $\mathrm{Mg}^{+2}$ da solução foi em $\mathrm{pH}$ 5,57 e a morfologia do produto é favorecido nesse $\mathrm{pH}$. Abaixo desse $\mathrm{pH}$ os cristais formados apresentaram morfologia esférica.

Palavras-chave: Cristalização; Alta Temperatura; Minério Laterítico; Monohidratado.

\section{INFLUENCE OF PH ON THE MORPHOLOGY AND REMOVAL OF MAGNESIUM FROM NIQUEL LEACHEATE LICOR}

\section{Abstract}

Sulfuric acid leaching of laterite ores results in the generation of large volumes of waste that are sent to waste barriers. However, it is possible to recover the metals present in the barriers. Amongst the metals present in the waste barriers is magnesium, which can be removed by high temperature crystallization. Factors such as temperature, $\mathrm{pH}$, agitation and residence time may affect the morphology of the final product and percentage removal of magnesium from the solution. Therefore, the present study proposes to evaluate the influence of $\mathrm{pH}$ on the removal of $\mathrm{Mg}^{2+}$ from a synthetic solution and to analyse the morphology of the crystals formed. The technique used was high temperature and pressure crystallization, carried out in a pressure reactor. The $\mathrm{pH}$ was varied in the range of 1-5 using $\mathrm{H}_{2} \mathrm{SO}_{4}$. Temperature, residence time and stirring speed were kept constant at $230^{\circ} \mathrm{C}, 5$ hours and 1000 rpm, respectively. The residual solution was analysed by ion chromatography and crystal morphology by SEM-EDS. The highest removal of $\mathrm{Mg}^{2+}$ from the solution was

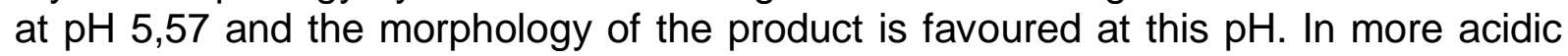
media the crystals formed presented spherical morphology.

Keywords: Crystallization; High Temperature; Lateritic Ore; Monohydrate

1 Engenharia Química, Mestranda, Departamento de Engenharia Química, Escola Politécnica da Universidade de São Paulo, São Paulo, São Paulo, Brasil.

2 Engenheira Metalurgista, doutora em engenharia metalúrgica, professora associada, Departamento de Engenharia Química, Escola Politécnica da Universidade de São Paulo, São Paulo, Brasil.

3 Engenheiro Metalurgista, Doutor em Engenharia metalúrgica, Professor Titular, Departamento de Engenharia Química, Escola Politécnica da Universidade de São Paulo, São Paulo, Brasil 


\section{INTRODUÇÃO}

Níquel é encontrado naturalmente em minérios sulfetados e lateríticos. O minério laterítico é formado próximo a superfície e é classificado em três zonas: limonita, nontronita e saprolito/garnierita/serpentina e devido ao intemperismo cada zona possui diferentes teores de níquel e outros metais [1].

Apesar de aproximadamente $70 \%$ do minério de níquel ser constituído de minério laterítico e o restante de minério sulfetado, mais de $60 \%$ da obtenção de níquel é proveniente do minério sulfetado [2]. Porém, com a alta demanda de se processar níquel ao longo dos anos, houve uma redução na disponibilidade dos minérios sulfetados e para atender a demanda futura de níquel, há uma quantidade crescente de níquel sendo extraído a partir de minérios laterítico.

O processamento do minério laterítico é considerado mais complexo devido ao baixo teor de níquel contido no minério dessa origem e ao processamento rigoroso necessário para a dissolução completa dos metais [3].

Os minérios lateríticos são comumente processados através da rota hidrometalúrgica que consiste na lixiviação ácida com ácido sulfúrico onde os metais são dissolvidos em uma solução aquosa [3]. Essa lixiviação ácida resulta num licor que, além de conter níquel dissolvido, também possui outros metais dissolvidos que precisam ser recuperados. A composição típica dos metais dissolvidos no licor está apresentada na Tabela 1.

Nesse contexto, é indispensável que o licor de lixiviação sofra uma série de procedimentos para a remoção das impurezas como alumínio, zinco, cromo, ferro, manganês e magnésio [2].

Tabela 1. Composição típica do licor de lixiviação do minério laterítico de níquel [2]

\begin{tabular}{cc}
\hline Metal & Concentração $\mathbf{( g / L )}$ \\
\hline $\mathbf{N i}^{2+}$ & 5,0 \\
$\mathbf{C o}^{2+}$ & 0,3 \\
$\mathbf{F e}^{3+}$ & 23,0 \\
$\mathbf{A l}^{3+}$ & 6,0 \\
$\mathbf{C r}^{3+}$ & 1,0 \\
$\mathbf{M n}^{2+}$ & 1,0 \\
$\mathbf{M g}^{2+}$ & 8,0 \\
\hline
\end{tabular}

O magnésio encontra-se no licor na forma de sulfato de magnésio e pode ser recuperado por precipitação ou cristalização [4][5][6]. Cristais de sulfato de magnésio são transparentes e as fases mais estáveis existentes são a monohidratada, com uma molécula de água, hexahidratada com seis moléculas de água e o heptahidratado, com sete moléculas de água. A estrutura cristalina da forma monohidratada é monoclínica, mostrada na Figura 1 [7][9]. 


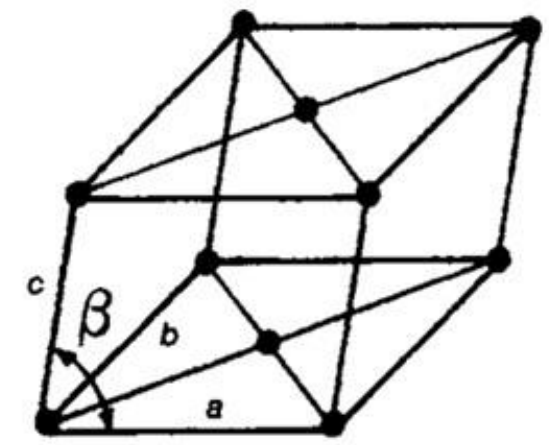

Figura 1. Estrutura cristalina do $\mathrm{MgSO}_{4} \cdot \mathrm{H}_{2} \mathrm{O}[9]$

O sal monohidratado apresenta uma solubilidade inversa, ou seja, a solubilidade diminui com o aumento da temperatura a partir de aproximadamente 70 ${ }^{\circ} \mathrm{C}$, como pode ser visto pela curva de solubilidade mostrada pela Figura 2. Portanto, para obtenção dessa forma hidratada o método apropriado é da cristalização a alta temperatura e pressão. Esse método é pouco estudado uma vez que as condições utilizadas são extremas, com pressão e temperatura do reator atingindo aproximadamente $30 \mathrm{~atm}$ e $230^{\circ} \mathrm{C}$, respectivamente.

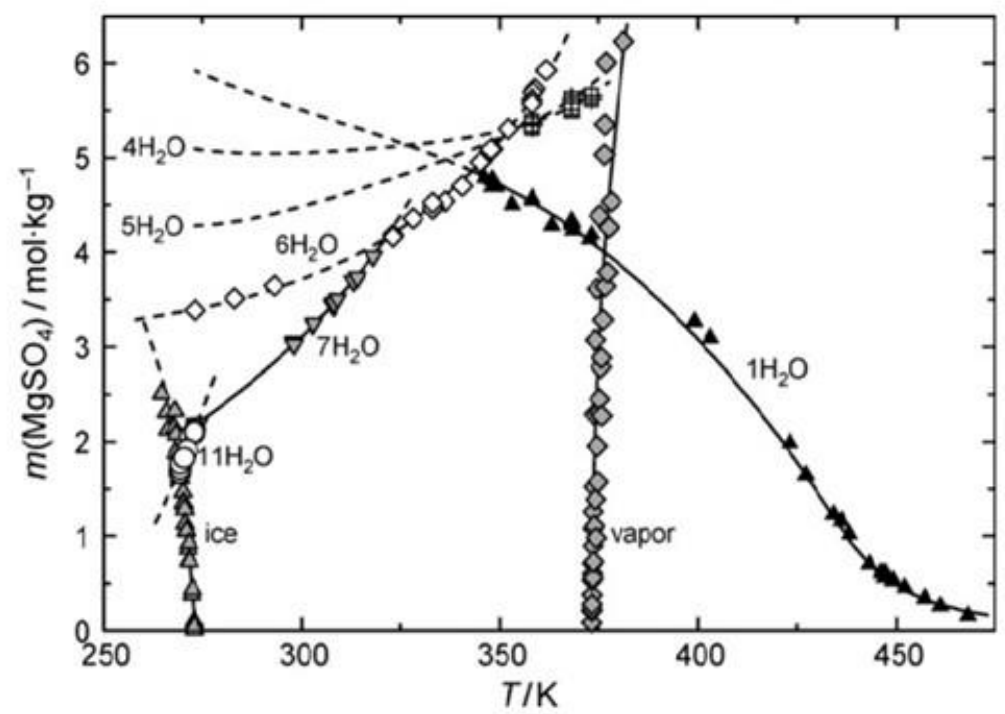

Figura 2. Solubilidade do sulfato de magnésio em água [10]

Esse método pode ser vantajoso para o processo de extração do níquel por lixiviação com ácido sulfúrico uma vez que o magnésio é recuperado da solução, gerando cristais puros sem a adição de um reagente. Os cristais formados, contendo somente uma molécula de água, necessitam de menos energia para se decompor em $\mathrm{MgO}$ e $\mathrm{SO}_{2}$ [8][11]. O $\mathrm{MgO}$ pode ser utilizado no processo na etapa de neutralização e $\mathrm{o} \mathrm{SO}_{2}$ pode ser encaminhado para uma planta de ácido sulfúrico e também retornar ao processo na etapa de lixiviação ácida do minério [5]. Desta maneira, além do processo ficar isento da utilização de reagentes precipitantes, os produtos formados retornam ao próprio processo.

Variáveis como temperatura, tempo de residência e agitação influenciam a cristalização [6][12]. Além dessas variáveis, o pH da solução mãe também pode influenciar a morfologia e quantidade de produto cristalizado de uma solução. 
Podder [13] verificaram em seu estudo que o $\mathrm{pH}$ influenciou a morfologia de cristais de sulfato de magnésio heptahidratados. A faixa de $\mathrm{pH}$ trabalhada foi de 2,0 até 5,0 [13]. A solução de pH igual a 2 apresentou cristais com menor tamanho. Em pH 5 os cristais formados apresentavam maior tamanho. Portanto, foi concluído que $\mathrm{pH}$ ácido resulta na formação de cristais menores.

Al-Jibbouri [14] realizaram um estudo sobre a influência do $\mathrm{pH}$ e impurezas na cristalização do epsomita (sulfato de magnésio heptahidratado). $\mathrm{O}$ pH da solução foi variado na faixa 2,5 até 8,6 e os resultados mostraram que a solubilidade do sal heptahidratado diminui em meio ácido e aumenta em meio alcalino. Portanto, a precipitação do sal heptahidratado é favorecida em soluções ácidas.

A Figura 3 mostra o diagrama de Pourbaix do sistema magnésio-água a $25^{\circ} \mathrm{C}$. Em soluções alcalinas é formado o hidróxido e óxido de magnésio. Já em soluções ácidas, o $\mathrm{Mg}^{+2}$ é estável e encontra-se dissolvido. Logo, como é desejável a obtenção de um produto puro constituído de sulfato de magnésio monohidratado, será estudado a cristalização do magnésio em meio ácido somente, uma vez que em meio alcalino hidróxido é formado.

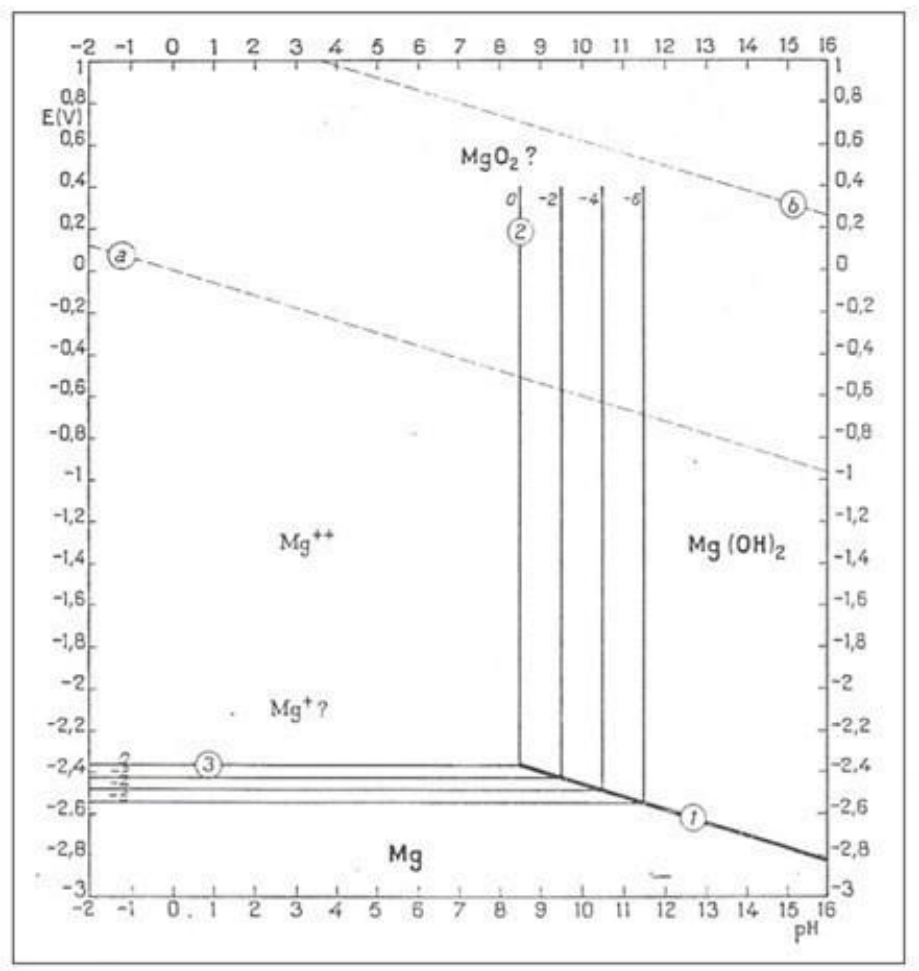

Figura 3. Diagrama de Pourbaix para o Sistema Magnésio-Água a $25^{\circ} \mathrm{C}[15]$

Tendo em vista que o $\mathrm{pH}$ da solução pode afetar os produtos, foi avaliado a influência do $\mathrm{pH}$ na remoção de $\mathrm{Mg}^{2+}$ de uma solução sintética e na morfologia dos cristais formados.

\section{MATERIAIS E MÉTODOS}


Uma solução sintética baseada na concentração de magnésio $(8 \mathrm{~g} / \mathrm{L})$ do licor de lixiviação industrial foi preparada com $\mathrm{MgSO}_{4} .7 \mathrm{H}_{2} \mathrm{O}$ de grau analítico e água deionizada. Foi utilizado um reator sob pressão feito de liga Hastelloy (Figura 4) em sistema batelada.

Inicialmente foi realizado um ensaio sem o ajuste do $\mathrm{pH}$ a $230^{\circ} \mathrm{C}$, tempo de residência de 5 horas e agitação $1000 \mathrm{rpm}$. O produto cristalino formado foi analisado por Difração de Raio-X (DRX) e por Microscopia de Varredura (MEV) e Espectroscopia por Dispersão de Energia de Raios X (EDS), a fim de verificar se o produto, produzindo nestas condições, era realmente constituído de cristais de sulfato de magnésio monohidratado.

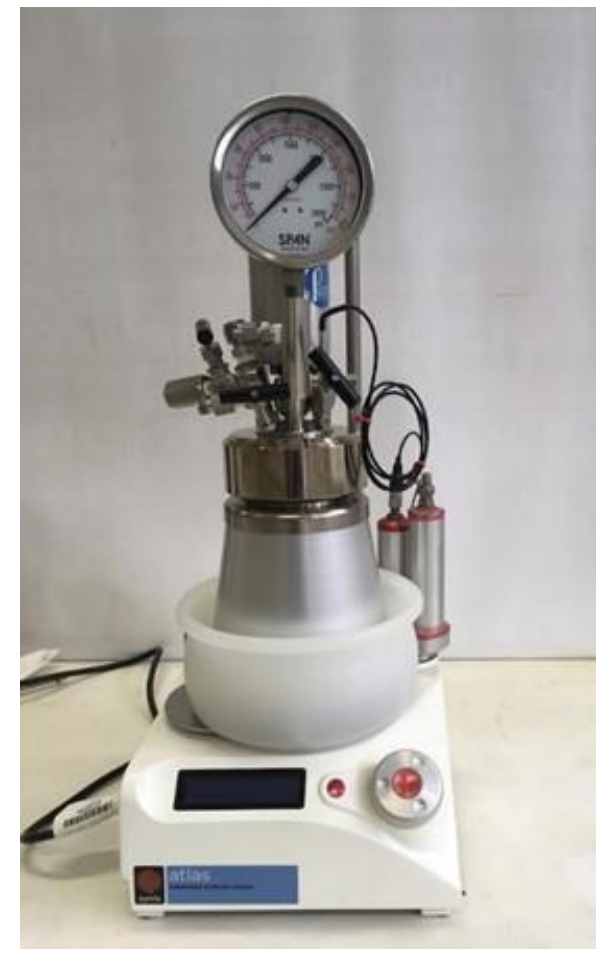

Figura 4. Reator sob pressão utilizado nos ensaios

$\mathrm{O} \mathrm{pH}$ inicial da solução sintética era em torno de 5,7 e o pH foi ajustado a temperatura ambiente na faixa de 1 até 5 em intervalos de 1 utilizando $\mathrm{H}_{2} \mathrm{SO}_{4} 1 \mathrm{M}$. Também foi realizado um ensaio sem alteração do $\mathrm{pH}$ original da solução mãe $(\mathrm{pH}=5,57)$. O pH das soluções foi medido com o uso de um pHmetro HI 2221.

A solução foi colocada no reator e a temperatura foi mantida constante a $230^{\circ} \mathrm{C}$, agitação igual a $1000 \mathrm{rpm}$, tempo de residência de 5 horas e pressão a 27 atm. Os ensaios realizados estão resumidos na Tabela 2.

Após cada batelada a solução foi filtrada. A solução residual foi analisada por cromatografia de íons e os cristais por MEV-EDS para verificar a morfologia do produto.

Tabela 2. Resumo dos ensaios com variação de pH 


\begin{tabular}{cccc}
\hline Ensaio & $\mathbf{T}\left({ }^{\circ} \mathbf{C}\right)$ & tempo $(\mathbf{h})$ & $\mathbf{p H}$ \\
\hline I & 230 & 5 & 1 \\
II & 230 & 5 & 2 \\
III & 230 & 5 & 3 \\
IV & 230 & 5 & 4 \\
V & 230 & 5 & 5 \\
VI & 230 & 5 & 5,57 \\
\hline
\end{tabular}

\section{RESULTADOS E DISCUSSÃO}

\subsection{Composição do Produto formado nas condições especificadas}

O produto formado nas condições especificadas era constituído por um pó branco. A Figura 5 mostra o difratograma obtido pela análise por DRX. Os picos são referentes ao sulfato de magnésio monohidratado, confirmando que o produto formado é composto por somente sulfato de magnésio monohidratado.

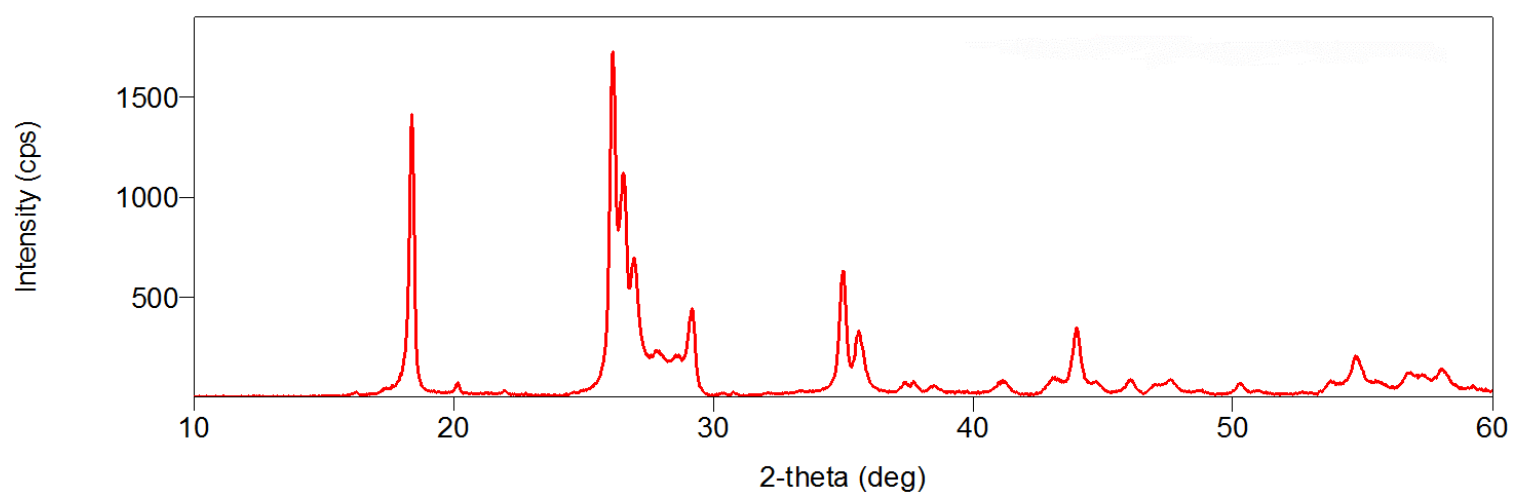

Figura 5. Difratograma do produto obtido por DRX

\subsection{Influência do pH da solução mãe na remoção do magnésio}

Após o término de cada ensaio, a solução filtrada foi analisada por cromatografia de íons para quantificar o magnésio na solução residual. A Tabela 3 apresenta a porcentagem de magnésio que foi cristalizado da solução para cada pH.

Tabela 3. \% Cristalização do $\mathrm{Mg}^{+2}$ em função do $\mathrm{pH}$ 


\begin{tabular}{cc}
\hline $\mathbf{p H}$ & \% Mg Cristalizado \\
\hline $\mathbf{1}$ & 2,99 \\
$\mathbf{2}$ & 41,17 \\
$\mathbf{3}$ & 3,79 \\
$\mathbf{4}$ & 45,11 \\
$\mathbf{5}$ & 41,42 \\
$\mathbf{5 , 5 7}$ & 80,10 \\
\hline
\end{tabular}

Com os dados da Tabela 3 foi construído um gráfico da porcentagem de magnésio removido da solução em função do $\mathrm{pH}$ da solução mãe, mostrado na Figura 6.

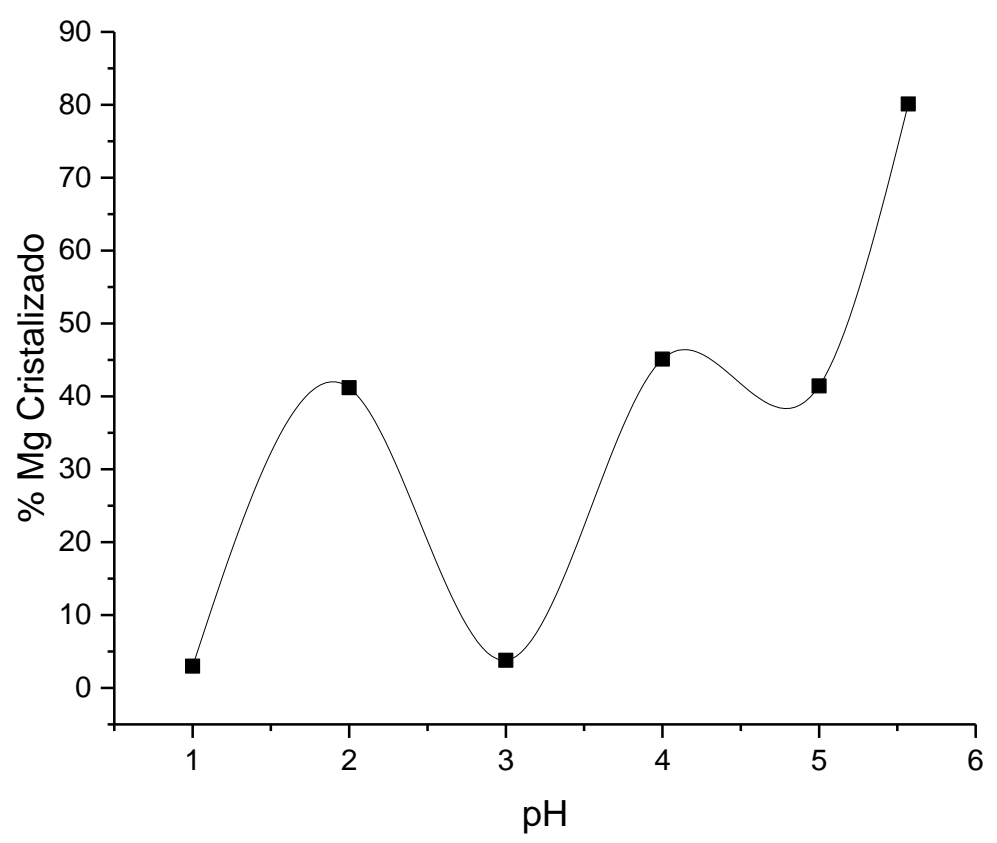

Figura 6. \% Cristalização do $\mathrm{Mg}^{+2}$ em função do $\mathrm{pH}$

A maior remoção de magnésio da solução foi referente ao ensaio sem o ajuste do $\mathrm{pH}$, com $80 \%$ de magnésio removido da solução. $\mathrm{Em} \mathrm{pH} 1$ e 3 a remoção foi mínima e em pH 2, 4 e 5 a porcentagem removida foi bem similar, em torno de $45 \%$.

\subsection{Caracterização dos Cristais}




\section{Microscopia Eletrônica de Varredura (MEV) e Espectroscopia de Energia Dissipativa (EDS)}

A

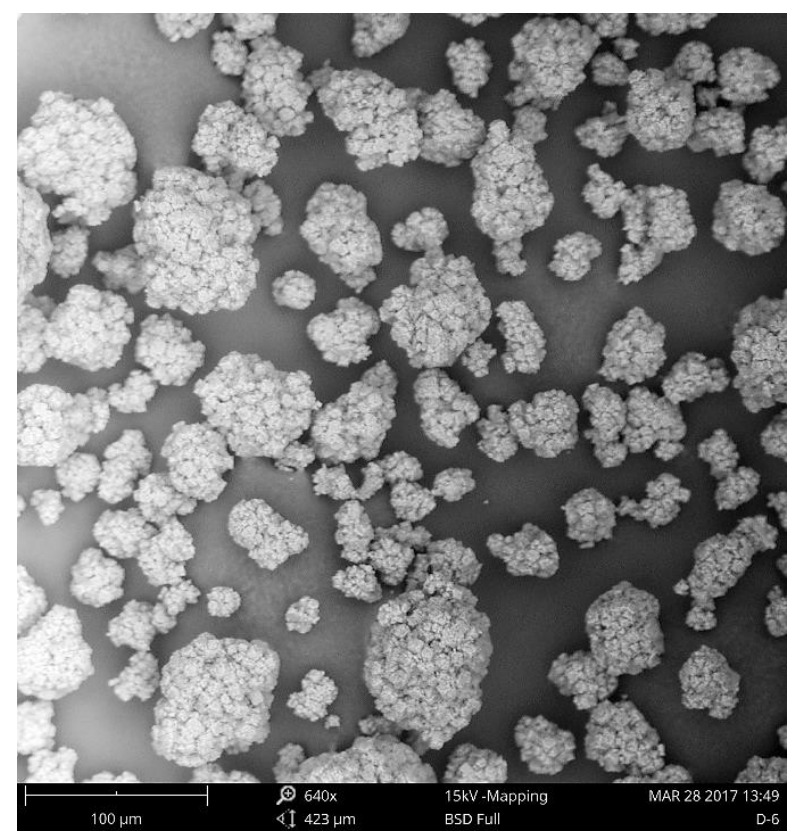

C

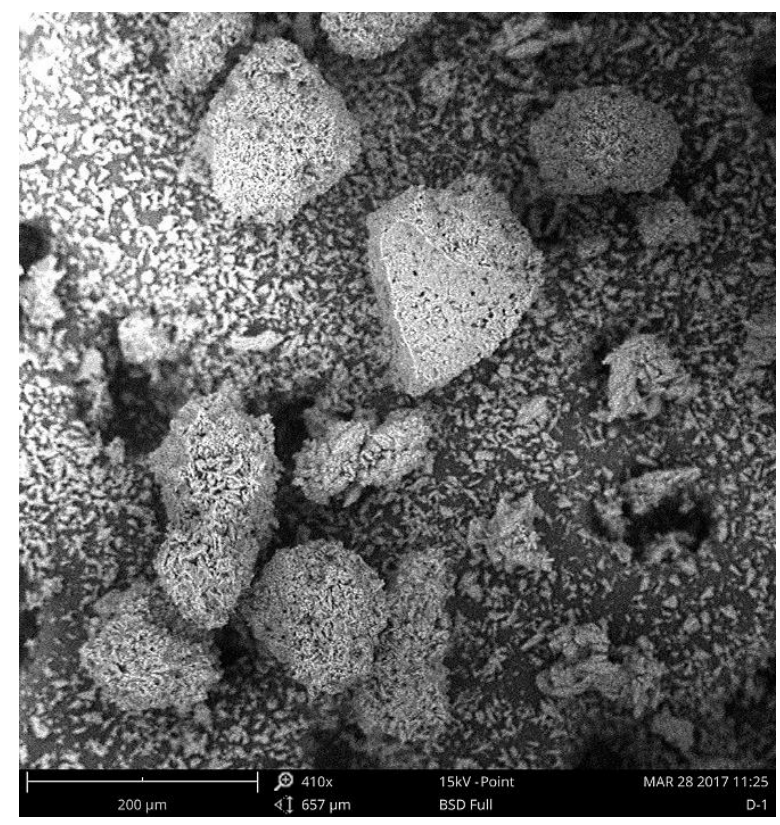

B

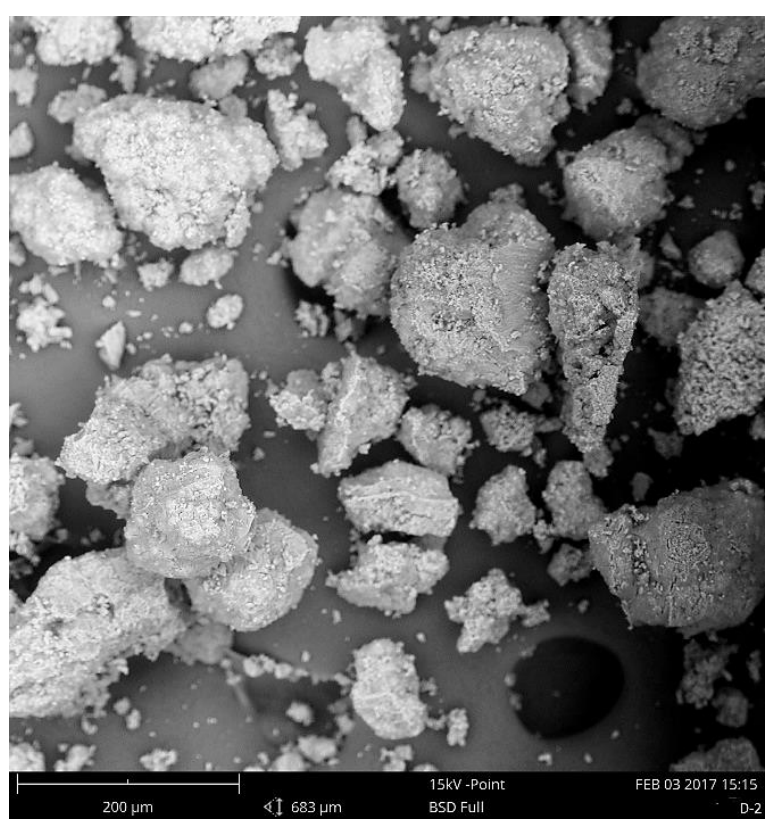

D

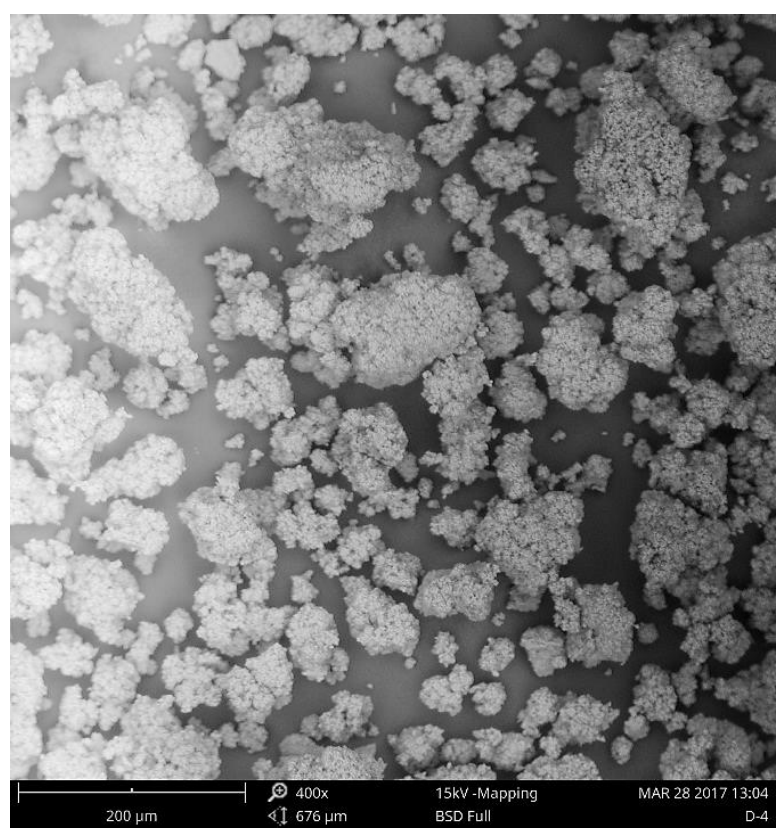


$\mathrm{E}$

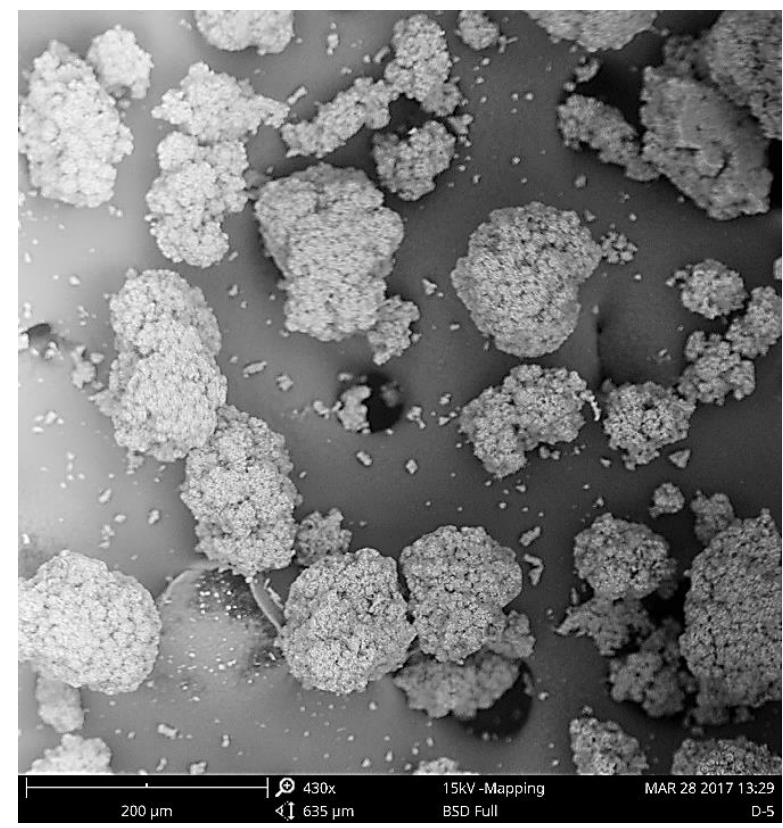

$\mathbf{F}$

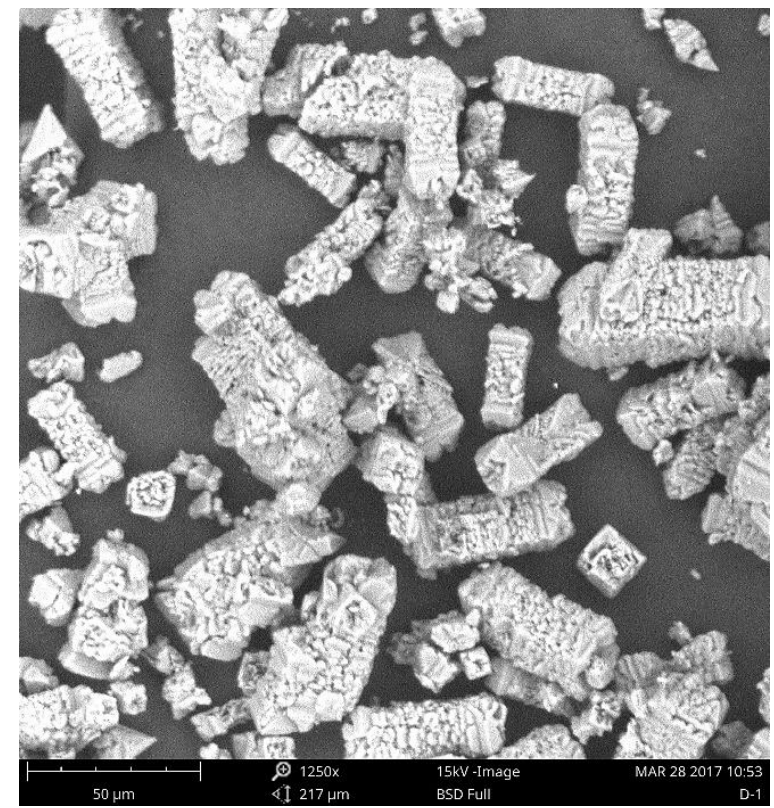

Figura 7. Figura obtida por MEV dos cristais formados a A) $\mathrm{pH} 1$; B) $\mathrm{pH} 2$; C) $\mathrm{pH} 3$; D) $\mathrm{pH} 4$; E) $\mathrm{pH} 5$ e F) 5,57 (sem ajuste do pH da solução mãe).

A Figura 7 mostra as imagens obtidas por MEV para cada $\mathrm{pH}$ ajustado da solução mãe. Observa-se a formação de cristais monoclinicos (retangulares) em pH 5,57 , Figura 7-F, e ao diminuir o $\mathrm{pH}$ os cristais formados apresentam froma esférica.

Os dados obtidos por EDS estao apresentados na Tabela 4. A composição elementar dos cristais obtidos a cada pH é constituída por magnésio, enxofre e oxigênio

Tabela 4. Composição elementar dos cristais obtidos a cada pH determinado por análise EDS.

\begin{tabular}{cccc}
\hline & \multicolumn{3}{c}{ Porcentagem Atômica (\%) } \\
pH & Mg & S & O \\
\hline $\mathbf{1}$ & 20,9 & 14,9 & 64,2 \\
$\mathbf{2}$ & 21,5 & 13,9 & 64,8 \\
$\mathbf{3}$ & 20,8 & 14,5 & 65,7 \\
$\mathbf{4}$ & 22,1 & 16,4 & 61,5 \\
$\mathbf{5}$ & 22,3 & 14,8 & 62,9 \\
$\mathbf{5 , 5 7}$ & 18,1 & 17,0 & 64,8 \\
\hline
\end{tabular}




\section{CONCLUSÃO}

O produto formado nas condições especificadas, sem ajuste do $\mathrm{pH}$, era constituído por somente sulfato de magnésio monohidratado, conforme confirmado pela análise por DRX.

2,$99 ; 41,17 ; 3,79 ; 45,11 ; 41,42 ; 80,10 \%$ do magnésio foram precipitados em $\mathrm{pH} 1,2,3,4,5,5,57$ respectivamente. $\mathrm{O}$ pH natural da solução $(5,57)$ apresentou maior cristalização do magnésio e pH 1 menor cristalização.

Os cristais formados em $\mathrm{pH} \mathrm{5,57} \mathrm{apresentaram} \mathrm{uma} \mathrm{clara} \mathrm{estrutura} \mathrm{cristalina}$ monoclínica. Já em $\mathrm{pH} 2$ e 3 é possível ver que os cristais de formatos variados, indicando um crescimento não homogêneo. $\mathrm{pH}$ menores que 5 apresentaram um formato esférico. Portanto, a variação do $\mathrm{pH}$ afeta a formação dos cristais, sendo que em meios mais ácidos o crescimento e desenvolvimento da estrutura cristalina não são favorecidos.

\section{Agradecimentos}

Ao Instituto Tecnológico da Vale (ITV) pelo apoio financeiro à bolsa de mestrado. À Fundação de Amparo à Pesquisa do Estado de São Paulo (FAPESP) pelo auxílio financeiro através do projeto de pesquisa 2012/51871-9.

\section{REFERÊNCIAS}

1. Crundwell FK, Moats MS, Ramachandran V, Robinson TG, Davenport WG. Extractive Metallurgy of Nickel, Cobalt and Platinum Group Metals. Elsevier Ltd. 2011. p. 1-18.

2. Agatzini-Leonardou S, Tsakiridis PE, Oustadakis P, Karidakis T, Katsiapi A. Hydrometallurgical process for the separation and recovery of nickel from sulphate heap leach liquor of nickeliferrous laterite ores. Miner Eng. 2009;22(14):1181-1192.

3. Mudd GM. Global trends and environmental issues in nickel mining: Sulfides versus laterites. Ore Geol Rev. 2010;38(1-2):9-26.

4. Karidakis T, Agatzini-Leonardou S, Neou-Syngouna P. Removal of magnesium from nickel laterite leach liquors by chemical precipitation using calcium hydroxide and the potential use of the precipitate as a filler material. Hydrometallurgy. 2005;76(1-2):105-14.

5. Kay H. Treatment of nickelliferous oxidic materials for the recovery of nickel values. USA; 1969. p. 1-6.

6. Li J, Fan ZG, Liu YL, Liu SL, Jiang T, Xi ZP. Preparation of boric acid from lowgrade ascharite and recovery of magnesium sulfate. Trans Nonferrous Met Soc China (English Ed. 2010;20(6):1161-5.

7. Robson LR. The system MgSO4-H2O from 68 to $240^{\circ} \mathrm{C}$. $1927 ; 49$.

8. Scheidema M, Scheidema $M$. The reaction mechanism and operating window for the decomposition of hydrated magnesium sulfate under reducing conditions. [tese de doutorado]. Finland: Aalto University; 2015. 
9. Ginde R. Crystals, crystal growth and nucleation [Internet]. Handbook of Industrial Crystallization. Elsevier; 2002 [cited 2016 May 7]. 33-65 p. Available from: http://www.sciencedirect.com/science/article/pii/B9780750670128500045

10. Steiger M, Linnow K, Ehrhardt D, Rohde M. Decomposition reactions of magnesium sulfate hydrates and phase equilibria in the MgSO4-H2O and $\mathrm{Na}+-\mathrm{Mg} 2+-\mathrm{Cl}--\mathrm{SO} 42--\mathrm{H} 2 \mathrm{O}$ systems with implications for Mars. Geochim Cosmochim Acta [Internet]. 2011 Jun [cited 2016 Mar 30];75(12):3600-26. Available from: http://www.sciencedirect.com/science/article/pii/S0016703711002055

11. Scheidema MSM, Taskinen PP. Reductive Decomposition of Magnesium Sulfate. 2011;(January):1021-32.

12. Tian F, Qu H, Zimmermann A, Munk T, Jørgensen AC, Rantanen J. Factors affecting crystallization of hydrates. J Pharm Pharmacol. 2010;62(11):1534-46.

13. Podder J. Crystallization and characterization. 2001;(January):1-9.

14. Al-Jibbouri S, Strege C, Ulrich J. Crystallization kinetics of epsomite influenced by $\mathrm{pH}$-value and impurities. J Cryst Growth [Internet]. 2002 Mar [cited 2016 Mar 14];236(1-3):400-6. Available from:

http://www.sciencedirect.com/science/article/pii/S0022024801021728

15. Marcelo Pourbaix. Atlas of Electrochemical Equilibria in Aqueous Solutions. National Association of Corrosion; 2nd edition.1974. 